\title{
Research on the implementation of University Humanities Teaching
}

\author{
LiuJin, YiXiaohui
}

Nanchang Institute of Science \& Technology, Nanchang 330108,China

Key words: University Humanities; teaching innovation; humanistic quality; teaching quality

\begin{abstract}
In the severe employment situation, the present situation of University Humanities teaching is worrying, the teaching method is single and lack of timeliness, so that students lose the enthusiasm of learning Chinese language, students' humanistic quality and aesthetic taste can not be improved. Only when we fully understand the significance of University Humanities, can we change the way of teaching Chinese language teaching in Colleges and universities, and give full play to its unique functions in order to improve the quality of University Humanities teaching. The improvement and innovation of University Humanities teaching in this paper is of great significance to improve the comprehensive quality of university.
\end{abstract}

\section{Introduction}

University Humanities is an important public course in higher education, it can improve students' reading comprehension and application ability, broaden their horizons, plays a very important role in improving the humanistic quality of students. At the same time, University Humanities teaching is an important way to improve the comprehensive quality of the students, now more and more people pay attention to the strengthening of quality education, how to implement more effective classroom teaching of University Humanities, but also need to study the problem now.

\section{The present situation and problems of University Humanities Teaching}

The teaching method is single, unable to meet the needs of students. At present, many colleges and universities in China still use the traditional language teaching methods, the main form is teachers explains the knowledge, the student listens to the knowledge the teaching method, the teaching method is monotonous, the use of this type of teaching is not conducive to mobilize the students' enthusiasm, initiative and cultivate students' innovative thinking. At present, there is no innovation in the content of University Humanities teaching materials, is mainly based on the traditional ideas, the lack of appeal, out of the track of the real life, the lack of targeted, it can easily make students tired of classroom psychological. At the same time, the traditional point of view is that University Humanities class does not need to be combined with other teaching facilities, teachers only need textbooks, teaching plans. With the wide use of information technology and modern teaching methods, the traditional teaching methods have been difficult to meet the needs of Contemporary Students. Therefore, teachers must adopt modern teaching equipment to carry out classroom teaching, improve students' learning efficiency.

The lack of effectiveness in University Humanities classroom teaching, classroom teaching quality is not high. The lack of effectiveness in the University Humanities classroom teaching, the quality of classroom teaching is not high, which is the main factor affecting the smooth progress of Chinese teaching. At present, the teaching methods of University Humanities courses in many colleges and universities do not match with their own characteristics and professional situation, so that it is not effective to carry out the activities of Chinese teaching in universities. The course 
teaching should take the student as the main body of the study, if the student is in the passive study status, will cause the student to lose the study pleasure, then causes the language classroom the teaching quality is not high.

The overall quality of teachers needs to be improved. At present, in our country the language discipline of teachers is not high, many teachers are still the traditional teaching philosophy and teaching methods used in the new teaching requirements, students can not meet the real needs, leading to the teaching effect is not good. In addition, with the expansion of college enrollment scale, teachers need to teach a number of classes, the teacher's teaching energy is limited, no extra time and effort to improve their overall quality and teaching level.

College students do not attach importance to University Humanities. In recent years, when the students are looking for a job, employers have put forward the requirements of computer and Chinese, but there are very few units in the language ability to make demands. In the face of the grim situation, students will spend more time to learn Chinese courses and computer courses, while ignoring the language learning. Because they think that learning computer courses and Chinese courses can increase the advantages of finding a job. And some colleges and universities in order to adapt to the trend of the times, improve the employment rate of students, also relaxed the requirements of Chinese education. The universities pays attention to the foreign language teaching, but neglects the alma mater teaching, which causes the student to pay no attention to the mother tongue study.

\section{The necessity of carrying out research on University Humanities Teaching}

Follow the people-oriented teaching concept. In order to improve the overall quality of the people, the modern teaching is to transform the external knowledge into the students' intrinsic psychological quality, which lays a good foundation for the all-round development of students. The traditional teaching methods and teaching contents of Chinese language only pay attention to the mechanical memory and repeated training, ignoring the students' aesthetic ability and moral education. The goal of modern education idea is to combine Chinese teaching with quality education, Encourage students to establish the correct values and outlook on life, the concept of modern education is to set up the correct values and outlook on life for students, to promote the students to develop the correct learning habits and develop a strong self-learning ability, which requires the traditional classroom teaching model for research and reform.

In order to meet the nature of modern Chinese curriculum and educational objectives. In the 2001 edition of the Chinese language curriculum standard, the Ministry of education mentioned that language is the most important communication tool, it is an important part of Chinese culture, the Chinese language classroom has the characteristics of tool and humanity. Colleges and universities offer Chinese language courses, mainly in order to enable students to learn Chinese classics, enable students to understand the history and development of Chinese literature, and also can improve the students' reading comprehension ability and writing level, cultivate noble sentiment and literary aesthetic ability, form the correct aesthetic view and perfect personality. It also embodies the unity of the instrumental and humanistic characteristics of University Humanities. The so-called characteristics of tool, that is the ability to read, write and speak Chinese, students can acquire this ability by instilling teaching methods and mechanical imitation. But if we want to achieve the goal of humanity, we can not get through repeated training and simple imitation. In recent years, people pay more and more attention to the humanity of University Humanities. It is generally believed that Chinese education must focus on the cultivation of students' humanistic quality, so that they can carry forward the Chinese national culture. 


\section{University Humanities teaching reform}

Rich aesthetic experience combined with multimedia teaching equipment. Combined with the traditional Chinese language classroom and multimedia video, audio, pictures and text, Let the text described the boring content into vivid image of the screen graph, let the aesthetic object in the imagination of the specific expression of the text, the abstraction into visual and auditory stimuli, the silent words into sound flow, which creates a new aesthetic space for students. At the same time, teachers can also use the network teaching resources, the establishment of a teaching platform, will be extended to extra-curricular class in teaching, students in extra-curricular time in the network teaching platform for teaching materials, more and more multimedia courseware, which is conducive to the development of student learning time, improve the quality of students' learning.

The implementation of a variety of Chinese teaching practice. Chinese discipline has a strong application, it is not only the knowledge of teaching, and the main purpose is to cultivate the ability to learn the use of language. The traditional teaching mode makes the students lack the opportunity to use the language. Therefore, the place of teaching can not be carried out only in the classroom. For example: hold a speech contest, calligraphy competition, knowledge competition activities, by participating in activities, not only can show the students' talent, but also to cultivate students' practical ability. In addition, the film can be held to enjoy the activities, the film is a reflection of the social life of an art, it presents the author's understanding and perception of life, with rich cultural connotations. For example, after the students watched the film "The three Kingdoms", is interested in this book, and have to read this masterpiece, mobilize the enthusiasm of the students to study knowledge, cultivate their interest in learning.

Create free and equal classroom atmosphere. In the traditional teaching, teachers are often regarded as the embodiment of authority and truth, while students are passive acceptance of knowledge, "the container", the lack of humane care, the students' personality and diversity. So it is very important to create a free and equal atmosphere in the classroom, the teacher is no longer a class leader, but a guide to students' learning, teachers allow students to question their own views, to encourage the students to express their views in a view. Guide students to dare to challenge the textbooks of the theorem, so that students truly become the masters of the classroom, this is the modern education in the classroom teaching of Chinese language learning environment.

Improve the assessment form of University Humanities. University Humanities textbooks are "formal beauty and content beauty" of the classics, which requires teachers to fully tap the articles contained in the element of beauty, guide the students to feel and appreciate the beauty, so as to cultivate students' aesthetic ability. The assessment of University Humanities should take a flexible and open form, so that the overall quality of the students to conduct a comprehensive inspection, such as examination papers, you can add some subjective analysis questions and essay questions, let the students to their own views and thinking to carry out the reading of literary works, to understand the humanistic spirit contained in the article, let the students can perceive the social, know themselves, understand their own shortcomings. It is a requirement of modern teaching and innovation that teachers should evaluate the test paper with the open academic thinking.

\section{Conclusion}

The University Chinese inherits the Chinese classical culture, and also plays an important role in cultivating the humanistic quality, moral sentiment and aesthetic taste of the contemporary college students. Therefore, it is a huge systematic project to carry out the innovation and reform of University Humanities classroom, which involves many aspects of our university curriculum, 
including teaching objectives, teaching mode, teaching content innovation and so on. In addition, the reform of University Humanities teaching should be combined with the practical effect, this course can effectively improve the humanistic quality of college students and the ability to use the language, so that the University Humanities curriculum has become the media to cultivate college students' comprehensive quality and comprehensive strength. Now, the implementation of the reform and innovation of Chinese curriculum in Colleges and universities in China is still in the exploratory stage, and constantly strive to explore the needs of teachers and students, the classroom door can really play its role, to complete this course goal, the comprehensive quality, humanistic quality, aesthetic taste, reading ability of college students to get big increase.

\section{Acknowledgement}

The work was supported by the education reform project in Jiangxi with the project number JXJG-12-24-1 and the project name Research on the Implementation of University Humanities Teaching.

\section{Reference:}

[1] Song Yongyan. The direction of the reform of Chinese teaching in Higher Vocational Colleges under the new situation [J]. Journal of Jiamusi Vocational Institute, No. 05, (2016), p.12-13.

[2] Liu BO, Liu Yu. Higher Vocational University Humanities teaching some knowledge of [J]. Journal of Seeking Knowledge Guide, No.05, (2016), p.119

[3] Xue Xiaoling. Research on the inquiry teaching mode of Chinese teaching in secondary vocational school based on network video courseware [D]. Beijing Institute of Technology, (2015)

[4] Zhang Qi. Research on the application of "flipped classroom" teaching model in secondary vocational Chinese teaching [D]. Beijing Institute of Technology, (2015)

[5] Liu Yuee, Li Chenzhi. The Chinese "tools" and "humanism" pendulum and dynamic unified [J]. Journal of Teaching and Management, Vol. 28, (2015), p.45-47.

[6] Nan Xiang Hu. Liang Qichao's interest education thought and Its Enlightenment to the present Chinese teaching [D]. Harbin Normal University, (2015)

[7] Cao Yunbo. Research on the reform of Chinese Teaching in senior high school based on constructivism teaching theory [D]. Huazhong Normal University, (2014)

[8] Zhang Hexia. Analysis on the function orientation and characteristic teaching mode of University Humanities course in Higher Vocational Education [J]. Language Planning, Vol. 29, (2014) , p.13-14.

[9] Feng Dajian, Chi Baodong, Liu Ziqi College of Humanities Quality Education Online Teaching Thinking -- Nankai University University Humanities online course construction of [J]. Chinese University Teaching, No.08, (2014) , p.24-28.

[10] Wei Fangyuan. The teaching content of Chinese reading humanistic spirit from the perspective of [D]. Guangxi Normal University, (2014) 
[11] Cheng Yuan, Gong Beifang, Zhao Li, et al. The influence of Chinese curriculum standards on Chinese education in different periods [J]. Heilongjiang Education (Theory \& Practice), No.03, (2014), p.54-56.

[12] Tan Zhihong. Problems and Countermeasures of current University Humanities education [J]. Journal of Guangxi Science \& Technology Normal University, No.03, (2013) , p.109-111.

[13] Qian Xuchu, Yang Li. Study on the evaluation system of teaching quality in Higher Vocational Colleges: Construction of University Humanities curriculum quality evaluation system [J]. Journal of Jiangsu Open University, No.06, (2012.) , p. 32-34

[14] Yan Meiling. My opinion on the effectiveness of Chinese classroom teaching in Senior High School under the new curriculum standard [J]. Education Teaching Forum, 15, (2011): 239

[15] Yang Yanping, Yan Lingzhi. Research on the development of higher mathematics teaching under the environment of educational informatization [J]. Journal of Yellow River Conservancy Technical Institute, No.02 , (2011), p. 87-91.

[16] Zhu Shujuan. Current situation and Countermeasures of University Humanities teaching in Colleges and universities [J]. Journal of Jilin Teachers Institute of Engineering and Technology, No. 06, (2008) , p. 45-46. 